\title{
Control of Roasting Coffee Bean Degrees by Image Processing with Histogram Matching Technique and Bean Weight Normalization
}

\author{
Naruebett Krongkarb*, Thanawut Thanavanich, Atikhom Siri, Kamol Boonlom, Seksan Winyangkul \\ Center for Microwave and Robotic Technology, \\ School of Computer and Information Technology, Chiangrai Rajabhat University, Thailand
}

\begin{abstract}
In the last decade, the consumption of coffee in Thailand is rapidly growth, because of the taste of coffee roasting that needs to pass with high quality standards. Normally, roasting processes to obtain a quality of roasted coffee bean requires an expert with experiences in verifying colors of the roasted coffee beans. Previously, a roasting plant showed that roasting requires meticulous processes to deliver the quantity and quality of bean to meet the needs of consumers. Therefore, the researcher proposes a technique of image processing method in order to analyze the colors of roasted coffee beans with 8 standard colors. The histogram matching technique is used to identify the degree of roasted coffee colors. The experimental results show that the technique reveals an accuracy average of 92.5 percent, compared to the standard colors of roasting coffee beans. The error occurring from the similarity of coffee bean colors brings about the implementation of a physical technique to normalize the bean weight with the Histogram Matching which yields 100 percent of accuracy.
\end{abstract}

Keywords: Image processing, histogram matching, coffee bean roasting

\section{Introduction}

The coffee bean roasting is considered a process with sensitivity. To gain the coffee in each level, it is essential to have both expertise and experience in roasting method with good quality and color matching the 8level standard. Checking the degrees of roasting the coffee beans, it requires an expert with experiences in controlling the process. According to the study, the coffee beans, after being roasted, are in similar degrees of colors. This problem is subsequently resulted from different factors depending on the heat temperature as well as timing used for roasting. When roasting for certain time, the beans appear in similar shades causing a difficulty to classify the level of coffee beans.

In this research, it presents a method using the histogram matching process to control the colors of roasting coffee in 8 standard levels. The benefits of the research are able to be applied to the roasting control system for color clarification automatically without an expert. Additionally, it is contributed to further develop a coffee roaster in the industry.

In the next section, the researcher discusses on the basic theories and related works. Section 3 explains about the method of the proposed research. The last part in Section 4 and Section 5, the summary of findings and the conclusions are described respectively.

\section{Theory and Related Works}

Coffee beans are generally divided into two species. The first one is the Arabica coffee grown at 3,000 feet above sea level. The Arabica coffee yields the product continuously with pleasant smell. The Arabica coffee contains one time less caffeine than the other species, the Robusta. The coffee products of the global segment comprise of the Arabica 75 percent, and the rest is the Robusta. The Robusta coffee is planted a bit above the sea level and mostly grown in tropical countries. The taste and aroma are stronger than another one and it yields at 25 percent of global production as previously mentioned.

The roasted coffee is considered the most important step to retrieve the properties of coffee including the smell along with the rich and smooth flavors. In fact, coffee roasting requires heating between 180-240 degrees Celsius for about 10-20 minutes. The temperature and duration consequently affect the smell and taste of coffee. 
The intensity of the roasting is typically divided into 8 levels; Green Bean, Light Roast, City Roast, Full City Roast, Light French Roast, French Roast, Full French Roast and Italian Roast.

The OpenCV [1] is a Library in $\mathrm{C}++$ and Phyton for a development of application related to image processing. It is able to be applied on both Windows and Linux operation systems and supported by the Intel Corporation Limited. The OpenCV has core components comprising of $\mathrm{CV}$ - a basic and high level image processing command, MLL - a statistic calculation of the and clustering of data, HighGUI - a command of I/O system and a function used to save and load image, and CXCORE - a basic command of data structure.

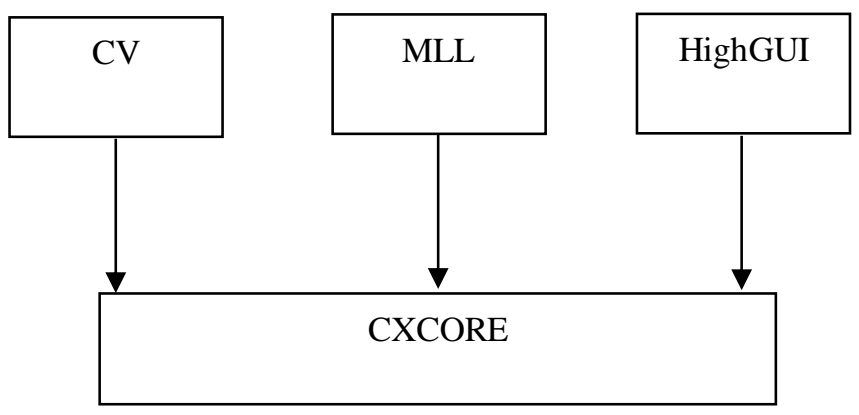

Fig. 1: OpenCV Structure

\subsection{Histogram Matching}

The Histogram Matching [10] is a function used for calculating pixels or pigments in each partition. When plotting a graph, the horizontal axis is the number of pixels or the division by number of partition whereas the vertical axis is the number of pigments or total pixels as shown in Figure 2.

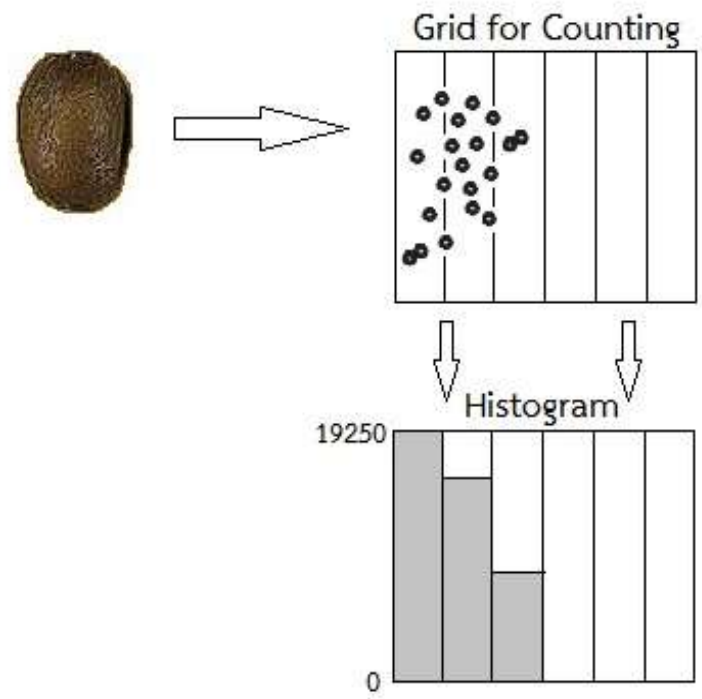

Fig. 2: Input image (upper left) is a partition divided and total pixel (upper right) and 1 dimensional Histogram graph (lower)

\section{Methodology}

The image processing to control the roasting of coffee beans initiates with 8 standard colors proceeded with the Histogram Matching program divided into 4, 8 and 16 partitions. The data are then stored into the database to compare with real coffee bean roasted as in Figure 3. 


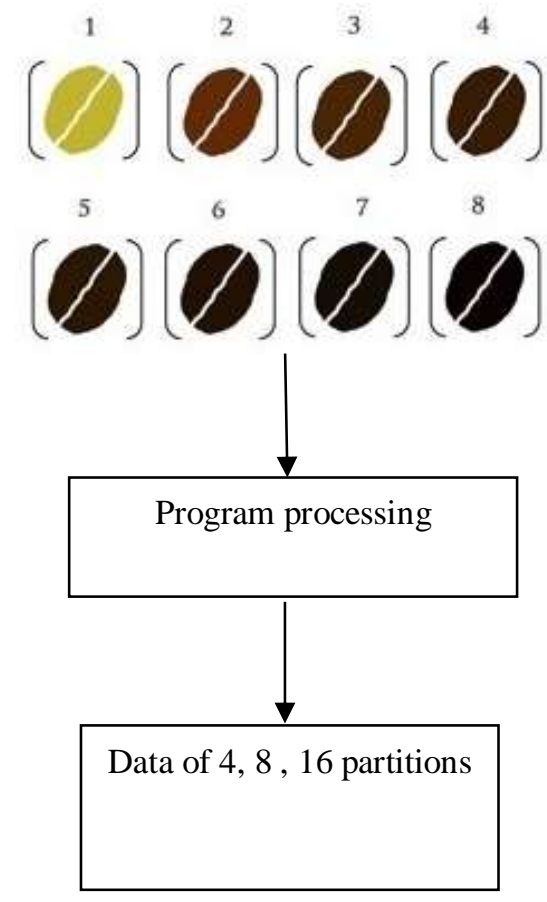

Fig. 3: Data collection of coffee bean standard colors

For a data set of 4, 8 and 16 partitions, it includes 3 data rows separated by ":". The first data of all 3 rows is 8 types of coffee beans. The second data of all 3 rows is the main RGB colors (b is blue, $g$ is green and $r$ is red). For the next until the last data, they are the number of pigment in each partition as in Figure 4, 5 and 6.

$$
\begin{aligned}
& 2: b: 19250: 0: 0: 0 \\
& 2: g: 19250: 0: 0: 0 \\
& 2: r: 0: 19250: 0: 0
\end{aligned}
$$

Fig. 4: The 4 partition database

$$
\begin{aligned}
& 3: b: 9600: 0: 0: 0: 0: 0: 0: 0 \\
& 3: g: 0: 9600: 0: 0: 0: 0: 0: 0 \\
& 3: r: 0: \theta: 9600: 0: \theta: 0: 0: 0
\end{aligned}
$$

Fig. 5: The 8 partition database

$$
\begin{aligned}
& 4: b: 19250: 0: 0: 0: 0: 0: 0: 0: 0: 0: 0: 0: 0: 0: 0: 0 \\
& 4: g: 0: 19250: 0: 0: 0: 0: 0: 0: 0: 0: 0: 0: 0: 0: 0: 0 \\
& 4: r: 0: 0: 6: 19244: 0: 0: 0: 0: 0: 0: 0: 0: 0: 0: 0: 0
\end{aligned}
$$

Fig. 6: The 16 partition database

The application of image processing with Histogram Matching for controlling the color of roasted coffee beans starts with processing the real roasted bean color and compared with the database with rating method. Final procedure will display the type of coffee bean as in Figure 7. 


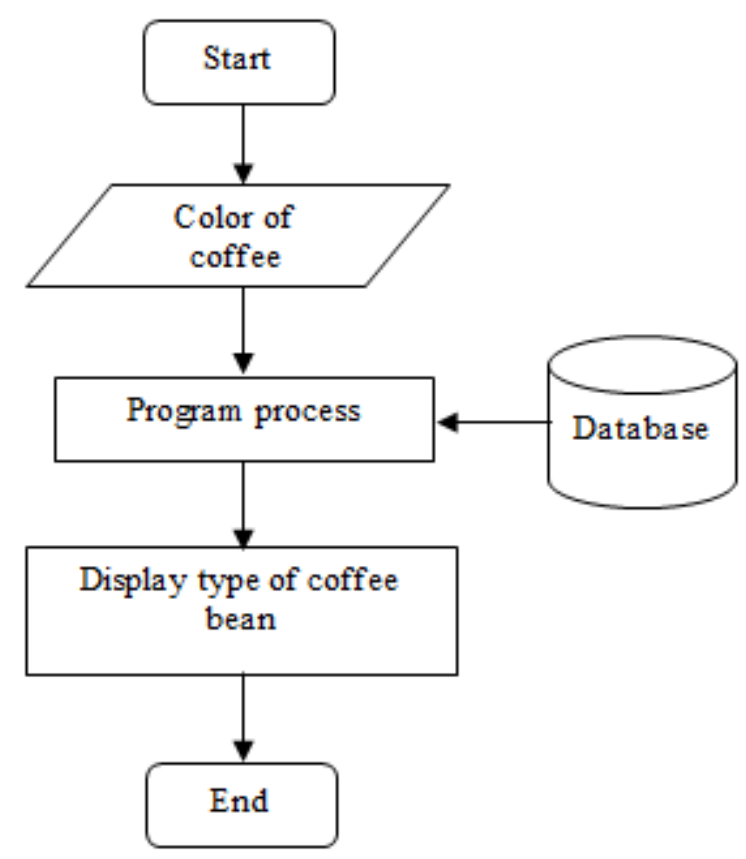

Fig. 7: The process of program

The comparison of real roasting beans by using the image processing to control the roasting procedure is separated into 5 images of real roasting beans. In comparison, data in 1 image is tested in 3 types compared to 4, 8 and 16 partitions. The experiment with 4 partitions, when the actual image processed into program, it reveals data in 4 partitions. Then, data is compared with database of 8 types. The evaluation is preceded by comparing partition by partition using 5\% of the deviation for each partition. If any partition is 0 , the deviation of $5 \%$ of maximum value in each row will be used. The score is rated as 1 when the partition compared is in the range of $5 \%$ of the deviation in the database. After scoring all models, the scores are then averaged by using the equation (1). For the 8 and 16 partitions, they are examined in similar way of 4 partitions. When the test is completed, the averages of all 3 models are compiled by using the equation (2) to find out a total average of each image. The experiment is conducted for 5 times, and the scores are compiled and averaged by the equation (1)

$$
\bar{X}=\frac{\sum x}{n}
$$

where $\begin{gathered}\sum x \text { is total score of each partition } \\ n \text { is total number of partition }\end{gathered}$

$$
\begin{gathered}
\text { Sum }=\bar{X}_{1}+\bar{X}_{2}+\bar{X}_{3} \\
\bar{X}_{1} \text { is average score of } 4 \text { partitions } \\
\bar{X}_{2} \text { is average score of } 8 \text { partitions } \\
\bar{X}_{3} \text { is average score of } 16 \text { partitions. }
\end{gathered}
$$

\section{Experimental Finding}

Analyzing the real roasted beans type 1 (Green Bean), the maximum value equals 2.25 matching the standard color type 1. Roasted coffee type 2 (Light Roast) reveals the maximum value of 2.2625 matching the standard color type 2. Roasted coffee type 3 (City Roast) reveals the maximum value of 2.104167 matching the standard color type 3. Roasted coffee type 4 (Full City Roast) reveals the maximum value of 2.416667 matching 
the standard color type 4. Roasted coffee type 5 (Light French Roast) reveals the maximum value of 2.25 matching the standard color type 5. For roasted coffee type 6 (French Roast), the maximum value is 2.070833 matching the standard color type 6. Roasted coffee type 7 (Full French Roast), the maximum value is 2.483333 matching the standard color type 7. Roasted coffee type 8 (Italian Roast), the maximum value is 2.545833 matching the standard color type 8 . All results are plotted as graph in Figure 8.

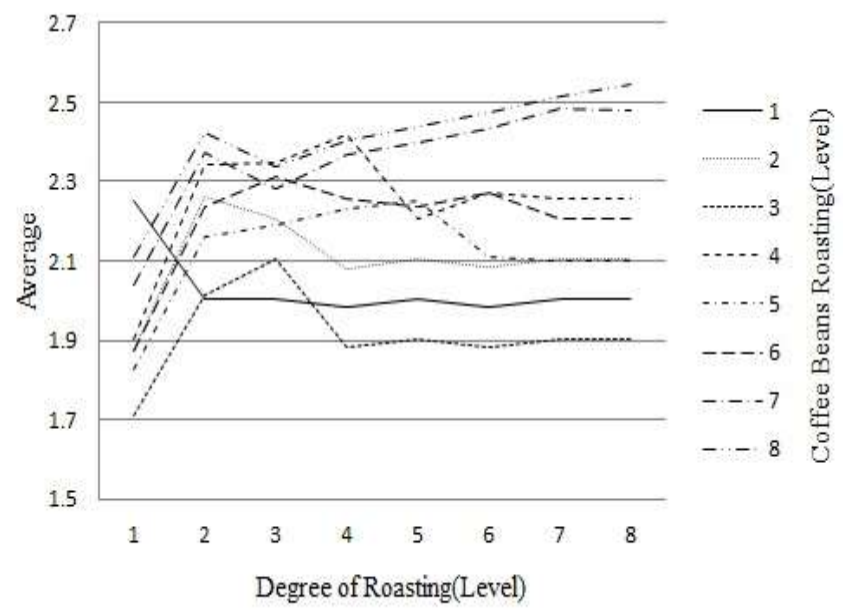

Fig. 8: Graph of the result

The significant problem occurred is that the 7th and the 8th levels of roasted coffee reveal similar shades which results in an error of classification. The process of Normalization is consequently employed. The process is applied with 50 coffee beans of each 7th and 8th level coffee to weigh and calculate for an average weight. The result is then multiplied by the average of image processing with the equation 3 . The Normalizing value of roasted coffee beans verified as 7 th level is between 9.483 to 10.947 while 8 th level is 14.124 to 15.861 .

$$
\operatorname{Sum}=\left(\bar{X}_{1}+\bar{X}_{2}+\bar{X}_{3}\right) / \mathrm{W}
$$

where $w$ is average weight of coffee beans.

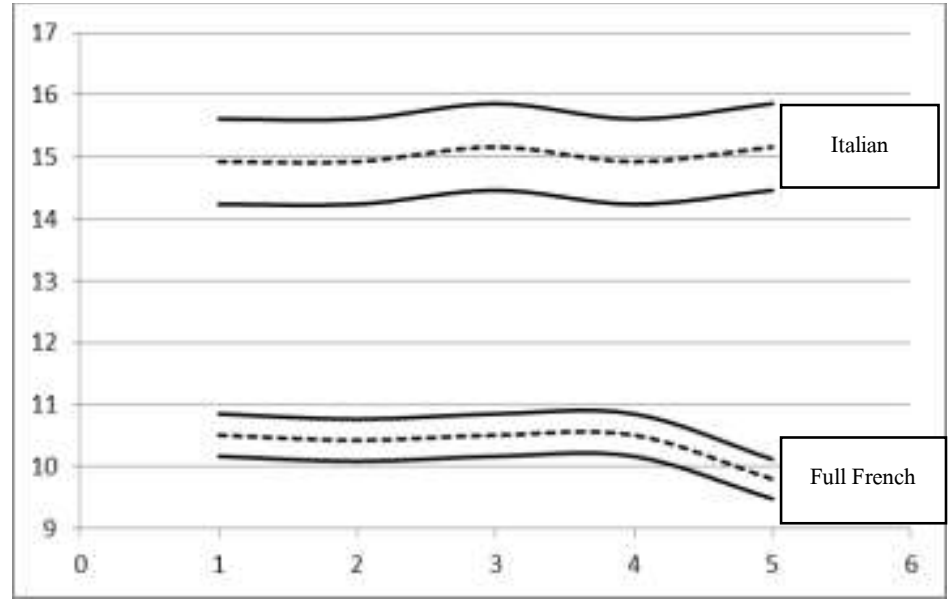

Fig. 7: Graph of an average of Normalized experiment 5 times

\section{Conclusion}

According to the comparison of roasting coffee beans by using the image processing program with the Histogram Matching to control degrees of roasting coffee color, the experiment is conducted for 5 times for 8 levels, totally 40times. The results are exhibited in Table I 
TABLE I: Result of experiment

\begin{tabular}{|c|c|c|c|}
\hline $\begin{array}{l}\text { Types of } \\
\text { coffee } \\
\text { bean }\end{array}$ & $\begin{array}{c}\text { Selected } \\
\text { (number of } \\
\text { image) }\end{array}$ & $\begin{array}{c}\text { Rate of } \\
\text { correctness } \\
(\%)\end{array}$ & $\begin{array}{c}\text { Deviation } \\
(\%)\end{array}$ \\
\hline Green Bean & 5 & 100 & 0 \\
\hline Light Roast & 5 & 100 & 0 \\
\hline City Roast & 5 & 100 & 0 \\
\hline $\begin{array}{c}\text { Full City } \\
\text { Roast }\end{array}$ & 5 & 100 & 0 \\
\hline $\begin{array}{c}\text { Light French } \\
\text { Roast }\end{array}$ & 5 & 100 & 0 \\
\hline French Roast & 5 & 100 & 0 \\
\hline $\begin{array}{l}\text { Full French } \\
\text { Roast }\end{array}$ & 3 & 60 & 40 \\
\hline Normalize & 5 & 100 & 0 \\
\hline Italian Roast & 4 & 80 & 20 \\
\hline Normalize & 5 & 100 & 0 \\
\hline $\begin{array}{c}\text { Average } \\
\text { Normalize }\end{array}$ & $\begin{array}{c}4.625 \\
5\end{array}$ & $\begin{array}{l}92.50 \% \\
100 \%\end{array}$ & $\begin{array}{l}7.5 \% \\
0 \%\end{array}$ \\
\hline
\end{tabular}

The comparison of roasted coffee beans by using the image processing to control roasting process reveals the efficiency of 92.5 percent. The problem occurred with coffee beans of type 7 and 8 is the difficulty to obviously clarify the shades which appear in similar colors. The solution is implemented by adding more partition to separate colors of the beans for more precision which enables the ability to specify the right type of coffee. When implementing the Normalization process, in contrast, the finding shows an effective result that is 100 percent of coffee bean clarification.

\section{References}

[1] Gary Bradski and Adrian Kaehler. Learning OpenCV. O’Reilly Media. Sebastopol, September 2008.

[2] J.A. Hernandez, B. Heyd and G. Trystram . On-line assessment of brightness and surface kinetics during coffee roasting. Journal of Food Engineering 87 (2008).

http://dx.doi.org/10.1016/j.jfoodeng.2007.12.009

[3] J.A. Hernández, B. Heyd and G. Trystram. Prediction of brightness and surface area kinetics during coffee roasting. Journal of Food Engineering 89 (2008)

http://dx.doi.org/10.1016/j.jfoodeng.2008.04.026

[4] M.C. Nicoli, M. Anese, L. Manzocco and C.R. Lerici. Antioxidant Properties of Coffee Brews in Relation to the Roasting Degree. Lebensm.-Wiss. u.-Technol., 30, 292-297 (1997)

[5] E.R. Dutra a, L.S. Oliveira a, A.S. Franca a, V.P. Ferraz b, R.J.C.F. Afonso c. A preliminary study on the feasibility of using the composition of coffee roasting exhaust gas for the determination of the degree of roast. Journal of Food Engineering 47 (2001)

[6] Daniel Lélis Baggio. Mastering OpenCV with Practical Computer Vision Projects. Packt Publishing Ltd, 2012

[7] Robert Laganière. OpenCV Computer Vision Application Programming Cookbook Second Edition. Packt Publishing Ltd, 2014

[8] Bjarne Stroustrup. The C++ Programming Language. Addison-Wesley, 2013

[9] Dougherty. Digital Image Processing Methods. CRC Press, 1994

[10] Paul Embree, Damon Danieli. C++ Algorithms for Digital Signal Processing. Pearson Education, 1998 